idleness, foppery, or tattiness of their assistants, and their juniors to counter with a cry of "exploitation." Practitioners in the eighteenth and nineteenth centuries, I am amused to note, were likely to discuss their horses with the gravity and enthusiasm they now lavish on their cars.

Appendices deal with doctor:population ratios and the relation between the numbers of doctors and other professions and-a nostalgic touch for some of us-include a table to show what drachms, minims, and scruples were. There are also potted biographies of the men who played a part in the development of medicine in those years. Not all of them were of the stature of
Wakley of the Lancet or had such a powerful platform for their prejudices. Many indeed were relatively obscure provincial practitioners whom we know only from their journals and day books or from a single publication on the subject of their hobby horse.

Dr Loudon is to be congratulated on a valuable and eminently readable contribution to the sociology of medicine. It should be read by anyone interested in finding out how we became what we are.

Medical Care and the General Practitioner 1750-1850. I Loudon. (Pp 368; £30.) Oxford: Clarendon Press, 1986. ISBN 0-19-822793-0.

\title{
Sick almost to doomsday
}

\author{
HUGH L'ETANG
}

Doctors seem so preoccupied with the fallout from nuclear war that they ignore its aetiology. Dr Bert Edward Park, a neurosurgeon who is taking a further degree in history, describes the neurological disorders in world leaders responsible for the lost peace of 1919, the drift to the second world war, and the beginning of the cold war in 1945.

His neurological and historical training enables him to emphasise the influence of those possibly regarded until now as minor figures. Woodrow Wilson, Franklin Roosevelt, and Adolf Hitler need no introduction, but Hindenburg, Pilsudski, and even Ramsay MacDonald are forgotten men. Woodrow Wilson wanted a League of Nations, Roosevelt an understanding with the Soviet Union, and Hitler his 1000 year Reich. Marshal Paul von Hindenburg, who became president of the Weimar republic in 1926, denigrated Hitler as a potential postmaster and stamp licker. Ramsay MacDonald, prime minister between 1929 and 1935-a longer period than that of the much maligned Stanley Baldwin and Neville Chamberlain combined-was guilty of appeasement before they succeeded him. Marshal Josef Pilsudski, a failed medical student, the virtual ruler of Poland from 1926 to 1935, was deluded about Poland's strength and Hitler's intentions.

Dr Park has reassessed the clinical condition of these tragic actors. He reviews Woodrow Wilson's stroke but attributes other neurological episodes to small lacunar infarcts due to hypertension, and his tic to hemifacial spasm. Hindenburg, aged 86 when Hitler seized power in 1933, had senile dementia, and Ramsay MacDonald, only 67 in 1933, was already showing signs of presenile dementia. Pilsudski, who died aged 68 , left his brain to the

university of Wilno. Available photographs of necropsy sections show cortical atrophy but no atherosclerosis.

Nor has the last word been said about Hitler. As if cholecystitis, Parkinson's disease, and the effects of polypharmacy were not enough, he may also have had temporal lobe epilepsy. This could explain his rage, aggression, paranoia, megalomania, and absences, together with those sudden attacks accompanied by delusions, hallucinations, or unexplained fears when he repeated stock phrases.

A different and revealing perspective is brought to Roosevelt's medical history. His failure was not just due to hypertension. In addition to hypertensive crises and, latterly, cardiac failure he had chronic obstructive pulmonary disease leading to what is now called secondary metabolic encephalopathy. Dr Park maintains that this is an intermittent phenomenon, which explains why Roosevelt had only brief periods of confusion when he seemed asleep. There is no evidence of dementia or, as has been claimed, of mental confusion when he met Churchill and Stalin in Tehran in 1943 and at Yalta in 1945.

Dr Park's shortest chapter deals with Winston Churchill's organic brain syndrome and Anthony Eden's problem with biliary tract obstruction and incidental medication, coinciding with the decline of Britain as a world power. Of more immediate importance is his chapter on future implications of illness in world leaders. Because of the American public's fascination with images he recommends an apolitical, prospectively selected, presidential disability commission entirely separated from the individual physician-patient relationship.
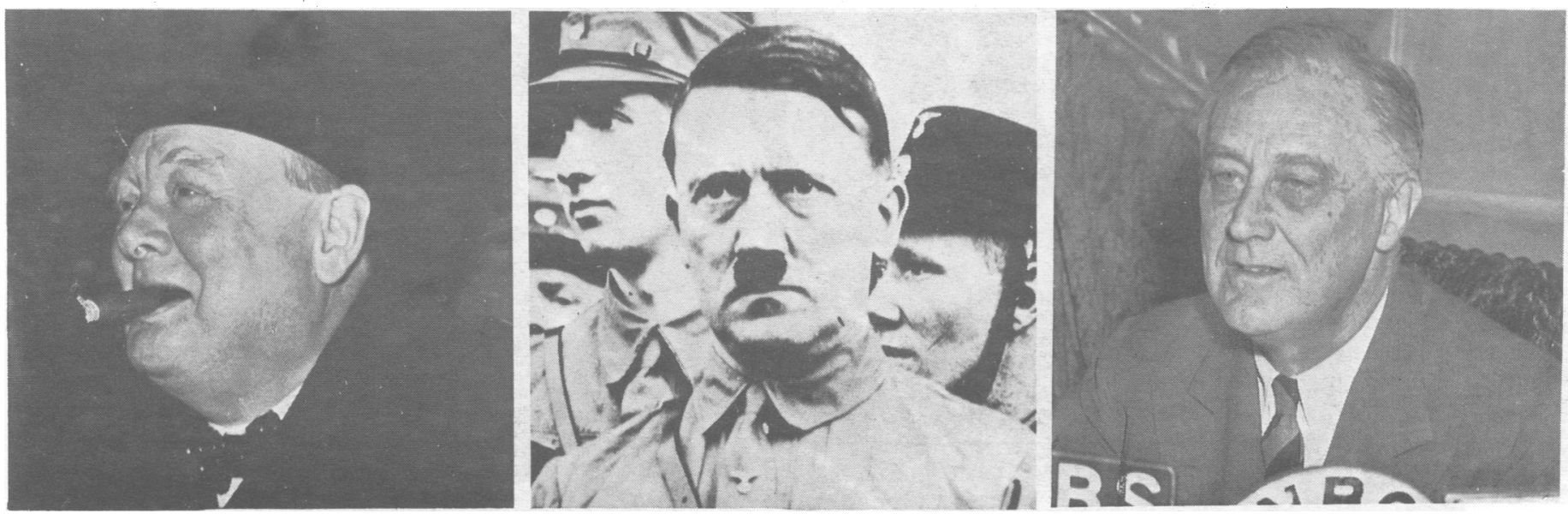

Churchill, Hitler, Roosevelt: their illnesses examined. 
Woodrow Wilson was given information and made decisions that he later forgot. Ramsay MacDonald did not remember initialling or reading a white paper on defence, nor did Roosevelt remember signing a disastrous plan in 1944 to remove all heavy industry from Germany. These instances of amnesia should not be dismissed as history for they are painfully reminiscent of events at the White House in 1987.

Dr Park has written a fascinating guide, not only to neurology and modern history but to the appraisal of national leaders, even though their appearances may be restricted to carefully rehearsed teleprompted photocalls on TV networks.

The Impact of Illness on World Leaders. B E Park. (Pp 373; figs; £22.) Philadelphia: University of Pennsylvania Press, 1986. ISBN 0-8122-8005-9.

\section{Central shame of Europe}

\section{J A THOMPSON}

In writing The Nazi Doctors $\mathrm{R} J$ Lifton's purpose is to uncover the psychological conditions conducive to evil, and to ask whether we are capable of learning from careful examination of a murderous episode in the recent past, the memory of which can neither be confronted and absorbed nor wished away.

His method has been to interview 29 high ranking old Nazi doctors, 12 Nazi non-medical professionals, and 80 former Auschwitz prisoners who worked on the medical blocks, more than half of them doctors. The Nazis presented themselves as decent people who had made the best of a bad situation, yet gave an account in which the narrator, morally speaking, was not quite present. Lifton is quite open about the methodological perils of a privileged American Jewish psychiatrist interviewing, through translators, old Nazi doctors about their part in the holocaust. His unfamiliarity with German denies him some of the immediate insights that Hannah Arendt used most devastatingly in her study of Eichmann. Her ear for the "language rules" and banalities of expression provided a great insight into the psychological mechanisms whereby people dulled their consciences while carrying out their murderous acts. Both authors, however, are trying to struggle with the central shame of the European age, and to understand how ordinary people could commit the demonic act of industrialised genocide.

\section{Perversion of standards}

Lifton's view is that medicine provided one of the central analogies of the Third Reich. It was not a matter of a few doctors mistreating their patients. What medicine offered was the analogy of a nation becoming healthy by purging itself of the Jewish illness, by extirpating a gangrenous appendix. Notions within German medicine were picked up, amplified, and encouraged in order to pave the way for the Final Solution. Doctors were enthusiastic converts to the fascist cause. With few exceptions, they collaborated in the early measures against the Jews, perverting their academic standards by consenting to have separate reference lists for work done by Jewish authors.

Naturally, as Jews began to be demoted from their status as doctors, German physicians were able to reduce the competition and gain promotion and advantage. Theories about euthanasia were amplified so that it became easy to talk of mercy killing as "the right to death" and to say that hopeless cases represented "life unworthy of life." The conclusion was that the state must own death-must kill-in order to keep the social organisation alive and healthy. By staging films and demonstrations of the repulsive behaviour of mistreated psychiatric inmates they were able to encourage requests for mercy killings that could eventually be linked with military aims, arguing that war needs a healthy people and that hospital beds should be set aside in preparation for the wounded.

The plan that they followed was to kill handicapped newborn babies and then the very young, doing this as if treatment were to be given, so that death was conceived of as therapy. Handicapped children were "put to sleep" by junior doctors who believed that this had been approved by higher command. This progressed on to the killings of juvenile delinquents and early experiments in killing psychiatric patients by mass gassing. Doctors participated by

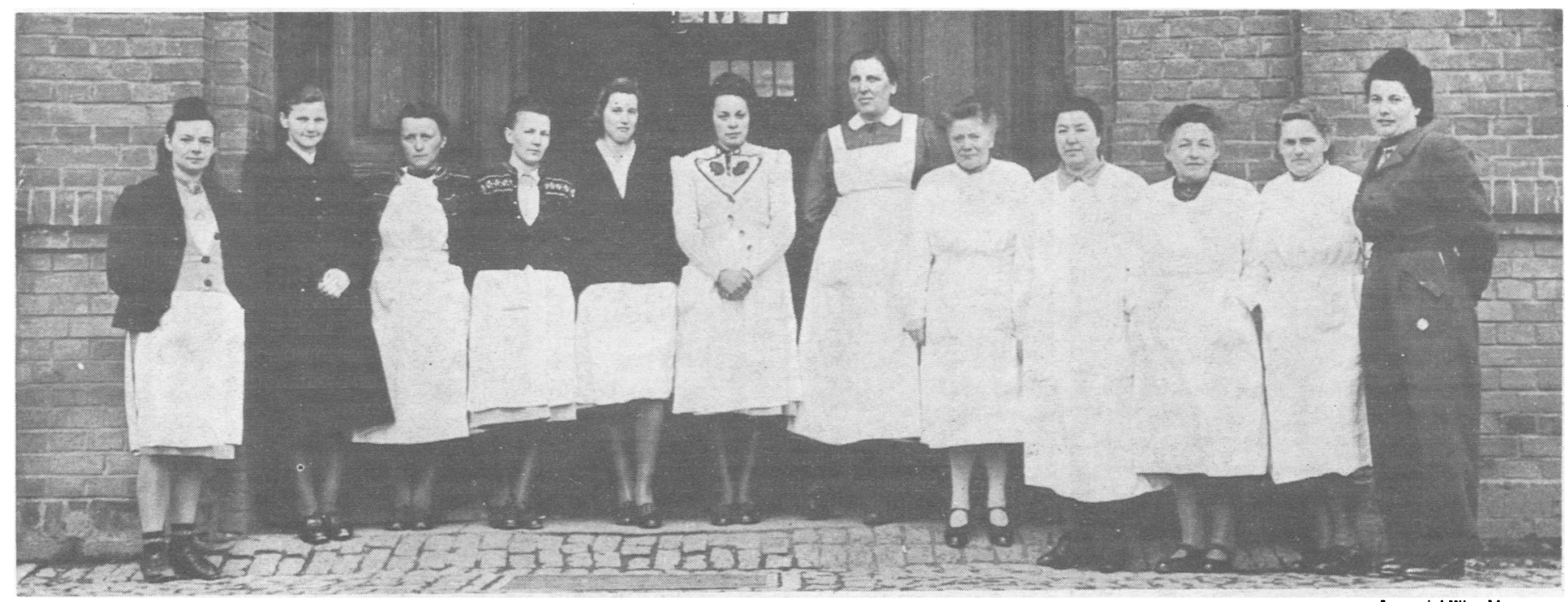

Staff at Hadamar hospital attached to Mauthausen concentration camp. 